\section{THE FERMILAB POLARIZEd DEAM SHAKE ${ }^{\dagger}$}

David G. Underwood

Argonne National Laboratory, Argonne, IL 60439

$$
\text { ANL-HEP-CP- } 88-70
$$

\section{ABSTRACT}

We describe the design and operation of spin rotators in the Fermilab polarized beam. The two modes of operation transform horizontal polarization to longltudinal or vertical. These can be considered partial snakes of type II and type I respectively. The required magnet properties are also discussed,

\title{
SPIN ROTATOR
}

We need a spin rotator, loosely called a Siberian Snake, for several reasons. First, we want to reverse the polarization direction In each element of phase space perlodically in order to control systematic errors in physics experiments. Secondly, we want to use vertical polariation in some experiments and longitudinal in others. Our beam provides transverse horizontal polarization.

Our rotator precesses the proton or anti-proton spin with a set of magnets with flelds transverse to the beam direction. The combinations of magnets chosen cancel the bends and displacements of the trajectories while leaving a net 90 degree spin transformation. The overall snatce appears to be a drift space for trajectories to very good approximation.

The overall snake consists of 12 magnets, each of which can precess the spin by 45 degrees. These are electrically connected as either of two rotator configurations which fundamentally use 8 bends. These two configurations are described in a NIM article.1 For precessing horizontal polarization (S type) to vertical (N type) we use 8 magnets of 45 degree precession. This is a type I partial snake with rotation of 90 degrees. Numbers $3,5,6,7,8,9,10$, and 12 of the 12 magnets are used. This is solution 524 in the NIM article. In the case of precessing horlzontal (s) to longitudinal (L), 4 of the basic 8 magnets require 90 degree precession, and each of these are made up of two magnets of 45 degrees, so that all 12 magnets are utilized. This is solution DZ4 in the NIM paper. This is a type II partial snake. The operation of this snake is shown in Figs. 1 and 2 .

Each of these partial snakes can be continuously varied down to zero overall spin rotation while maintaining it's pure type I or type II character. Unequal supply currents are required. This is a feature we have not used but which provides an examle for partigl snakes for accelerators. A paper on this feature is forthcoming.

The rotator $1 \mathrm{~s}$ powered by two power supplles in the case of $S$ to $N$ with 8 magnets. Each set of 4 magnets which should give no net bead or displacement of the beam is in series on one supply. Similarly in the case of $S$ to $L$ with 12 magnets, there are 4 cancelling magnets in series on each of 3 supplies.

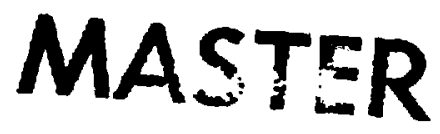


ix:

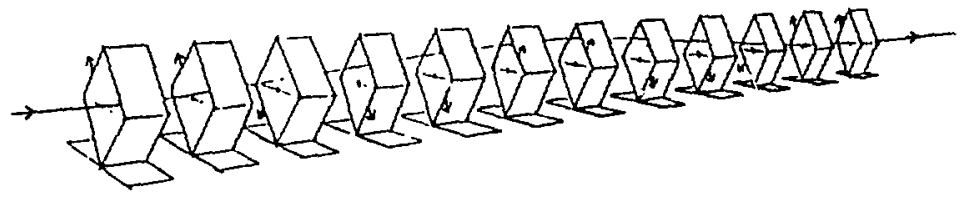

Flald, Looking d, . .

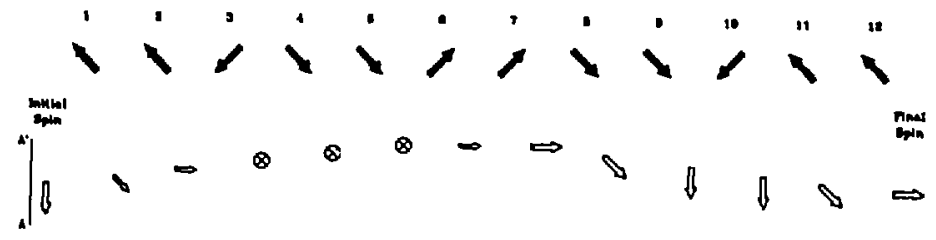

Beamiroid, 45 "side"

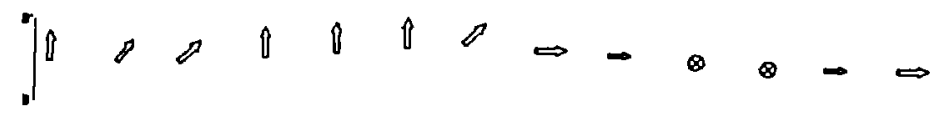

Polar.. looking d.

$\Leftrightarrow \infty \$ \$ \$$

palor. tep vien

Fig. 1. The type II solution as actually implemented in the Fermilab polarized beam. The overall rotation is $\pi / 2$ around the vertical axis. We have not used the continuously variable feature. Some of the magnets requiring higher strength are physically made of two magnets and so 12 magnets appear in this diegram.

a) The orbit and field directions.

b) The field directlons looking downstream.

c) The spin direction looking from below on the right.

d) The spin direction looking from above on the right.

e) The spin after each magnet, looking downstream.

f) The spin direction lookfing from directly above.

L:
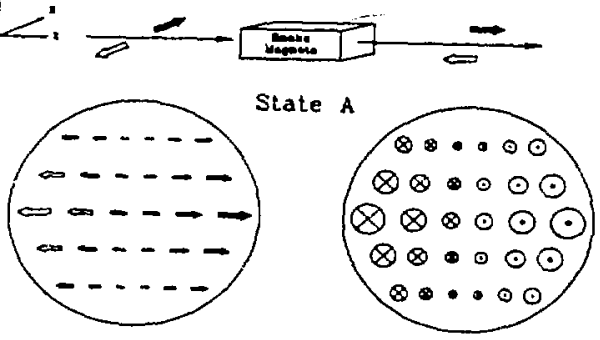

F1g. 2.

Idealized view of the transformation of the beam polarization and reversal of polarization direction

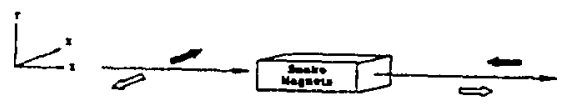

in the experiment.

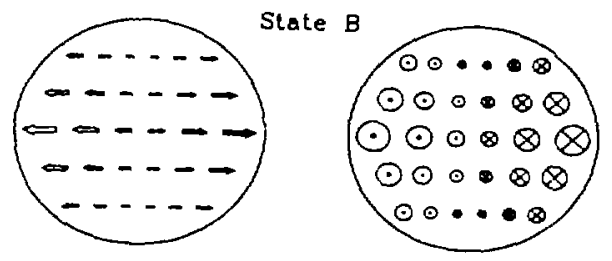


The rotators have amusing symmetry properties. These arise from the fact that they utilize non-commuting rotations and not simple single rotations. In order to reverse the final direction in the $N$ snake, only 4 of the 8 magnets are reversed. Reversing all 8 has no effect on the spin direction. Also in this case, the final rotation direction is the same for protons and for anti-protons, so that the overall effect which at first sight appears to be the same as that of a solenold actually has quite different properties. In order to reverse the final direction using the $S$ to $L$ snake, all magnets must be reversed. For this configuration the overall sense of rotation is opposite for protons and anti-protons.

Much effort went into the issue of field quality of the snake magnets. This was driven by the requirement that the snake appear as a drift space for particle tracking between sets of wire chambers, The angle of each beam track must be known to better than $2 \times 10^{-5}$ radian and no other stralght section is avallable for the track measurement. The requirements established by Monte Carlo and other methods are described later. The field quality achieved in the magnets meets the requirements and is summarized as follows: The most difficult constraint was the matching of the fleld integrals of the 12 magnets to within 1 part in $1 \times 10^{-3}$ at the same operating current. Within a magnet, the integral field variations within $\pm 5 \mathrm{~cm}$ of the axis are smaller than $3 \times 10^{-4}$. These come mainly from a negative sextupole term of about $5 \times 10^{-4}$ at $5 \mathrm{~cm}$ and a positive 10pole term of about $2 \times 10^{-4}$ at $5 \mathrm{~cm}$.

A simple estimate of the field quality requirements of the magnets can be made as follows: Each magnet will provide a kick of about $410 \mathrm{MeV} / \mathrm{c}$. We make the (not really valid) assumption that the errors from the 12 magnets can be added in quadrature. The required resolution on the centroid of a small element of phase space for many tracks can be as small as $3 \mathrm{MeV} / \mathrm{C}$. We want to make the same analysis on each element of phase space without making corrections for magnets. We also want the deviations in centroids to be at this level or smaller when some or all of the magnets are reversed. This gives $3 \mathrm{MeV} / \mathrm{c} / \sqrt{12}$ for the error in each magnet or a relative error of $2 \times 10^{-3}$.

A special purpose tracklng program was written to check in more detall what the effects of various errors and field components would do to the track reconstruction. There were two basic features of the program. 1) Trajectories were tracked with respect to a laboratory coordinate system, because the beam centroid was not in the center of the dipoles. The multipole expansion of the field was given in the center of the dipoles. 2) Track reconstruction assumed a wire chamber on each end of the snake, so that reconstruction was sensitive to both angular and displacement errors within the snake.

We were able to measure field integrals in a limited number of positions in the magnet aperture with errors typically $1.2 \times 10^{-4}$ of the central fleld. A Monte-Carlo program was used to find a resonably constralned multipole expansion. Theoretical constraints from the pole shapes with loose error bars were used along ith the field integral measurements both in and out of the magnet midplane with realistic error bars. 
The type I mode of this rotator was used for experiments in the Fermilab Polarized beam with both polarized protons and polarized anti-protons in 1987-1988..$^{3}$ Polarimeters showed that the spin components were as predicted within statistical errors. The beam deflection was measured in both type $I$ and type II modes and found to be less than $2 \times 10^{-5}$ at $185 \mathrm{GeV} / \mathrm{c}$.

$\dagger$

Work supported by the U.S. Department of Energy, Division of High Energy Physics, Contract W-31-109-ENG-38.

\section{REFEREMCES}

1. D. G. Underwood, "A Survey of Eight Magnet Spin Precession Snakes", Nuc 1. Instr. and Meth. 173, 351 (1980)

2. D. G. Underwood "Continuously Variable Snakes of Type I and Type II" ANL-HEP-PR-88-71.

3. B. E. Bonner et al., "Analyzing Power Measurement in Incluslve $\pi^{\circ}$ Production at High $x_{F} "$, Phys, Rev. Lett. 61, 1918 (1988). 


\section{DISCLAIMER}

This report was prepared as an account of work sponsored by an agency of the United States Governmert. Neither the United States Government nor any agency thereof, nor any of their employees, makes any warranty, express or implied, or assumes any legal jability or responsibility for the accuracy, completeness, or usefulness of any information, apparatus, product, or process discloced, or represents that its use would not infringe privately owned rights. Reference herein to any specific commercial product, process, or service by trade name, trademark, manufacturer, or otherwise does not necessarily constitute or imply its endoraement, recommendation, or favoring by the United States Government or any agency thereof. The views and opinions of authors expressed herein do not necessarily state or reflect thowe of the United States Government or any afency thereof. 